\title{
RECOGNIZING AND VALUATING INTANGIBLE RESOURCES - MAJOR DIFFICULTIES IN ORGANISATIONAL MANAGEMENT
}

\author{
Sebastian, STAN ${ }^{1}$, Dănut, DUMITRASCU² and Antonio, PELE ${ }^{3}$ \\ ${ }^{1}$ Lucian Blaga University of Sibiu, office.sstan@gmail.com \\ ${ }^{2}$ Lucian Blaga University of Sibiu, dumitrascud@asconet.ro \\ ${ }^{3}$ PUC-Rio - Pontifical Catholic University of Rio de Janeiro, antonio.pele.rj@gmail.com
}

\begin{abstract}
The measurement of intangible resources, intellectual capital, has become a major area of investigation for researchers and practitioners, with increasing concerns for monitoring and valuating this type of capital. In spite of this, the approaches to these issues have not been harmonised, therefore management is currently experiencing real difficulties in the assessment and measurement of intangible resources. In this article we wanted to review the valuation of intangible resources from a theoretical point of view, by highlighting the features of the most important valuation methods established in the literature.
\end{abstract}

KEY WORDS: intangible, resources, management, valuation

\section{INTRODUCTION: ORGANISATIONAL RESOURCES, VIEWED FROM STRATEGIC PERSPECTIVE}

Starting from the question: why are there significant differences in point of performance for firms operating in the same industry (i.e. they have the same exposure to macroeconomic factors that can stimulate or slow down their activity), we can answer them from the following explanation: since these firms are competing in the same industry and they experience similar external opportunities and threats, the source for some of the observable performance differences should be found within the firm. Thus, a look inside the firm to analyse its core resources, capabilities and skills will allow us to understand the firm's strengths and weaknesses.

In order to formulate and implement a strategy increasing the firm's chances of gaining and supporting competitive advantages, this must possess certain types of resources and capabilities that combine to form core competencies. The best performing firms rigorously identify their core competencies, resources and capabilities to survive and succeed. They then determines how to manage and develop their internal strengths to address the challenges and opportunities existing in their external environment.

Thus, the ability of an organisation to gain competitive advantages and to support them as well is partly determined by core competencies - strengths that are embedded deep within an organisation. The core competencies allow a company to differentiate its products and services from those of its competitors, creating greater value for customers or offering comparable products and services at lower costs.

Since core competencies are essential to gaining and sustaining competitive advantages, it is important to understand how they are created. Organisations develop core competencies through the interaction of resources and capabilities. Figure 1 shows this relationship. Resources can be tangible or intangible. Capabilities are the organisational and managerial skills required to orchestrate a diverse set of resources and implement them strategically. Thus, they have an intangible nature and they find expression in the structure, routines and culture of an organisation. As shown in Figure 1, these competencies are highlighted in the organisation's activities and they may lead to obtaining competitive advantages, resulting in increasing the firm's performance. Activities are distinct business processes such as order taking, physical delivery of products or customer invoicing. Every distinct activity allows organisations to add value by transforming inputs into goods and services. In the interaction between resources and capabilities, resources reinforce core competencies, while capabilities allow managers to orchestrate their core competencies.

The arrows going back from performance to resources and capabilities show that superior performance in the market generates profits that can be reinvested in the firm (profits nondistributed to shareholder) to further refine and further develop resources and capabilities in order to achieve and maintain a strategic evolution of the firm in a dynamic environment. But if core competencies are not fed continuously, they will eventually lose their ability to gain competitive advantages.

In analysing the success of a firm on the market, analysts often focus on more visible elements, or the facets of core competencies such as higher-end products or services. While these represent the outer manifestation of core competencies, what is even more important is the understanding of the invisible part of core competencies.

An organisation's external environment is rarely stable. Rather, in many sectors of activity, the change is very rapid. Firms failing to adapt their core competencies to this changing 35 
external environment do not just miss competitive advantages, but they may also come up with serious difficulties.

A core competency can turn into a basic rigidity if the organisation is based too much on that competency without its development, improvement and adaptation to the changes in the external environment. Over time, the original core competence no longer matches to the external environment and turns from an asset into a liability. That is why reinvesting, improving and developing resources and capabilities are crucial to sustain any competitive advantage. This skill is the basis of the dynamic capabilities perspective. This adds, as the name suggests, a dynamic or time element. More specifically, dynamic capabilities describe a firm's ability to create, implement, modify, reconfigure, and develop resources over time in its attempt to gain competitive advantage. Dynamic capabilities are essential to go beyond a short-lived advantage and create a sustained competitive advantage. For a firm, in order to sustain its advantages, any match between its internal strengths and the external environment must be dynamic. That is, the firm must be able to change its internal resource base together with the changes in its external environment. The goal should be to develop resources, capabilities and competencies that create a strategic match with the firm environment. Rather than getting a static fit, the firm's internal strengths should change with the external environment in a dynamic way.

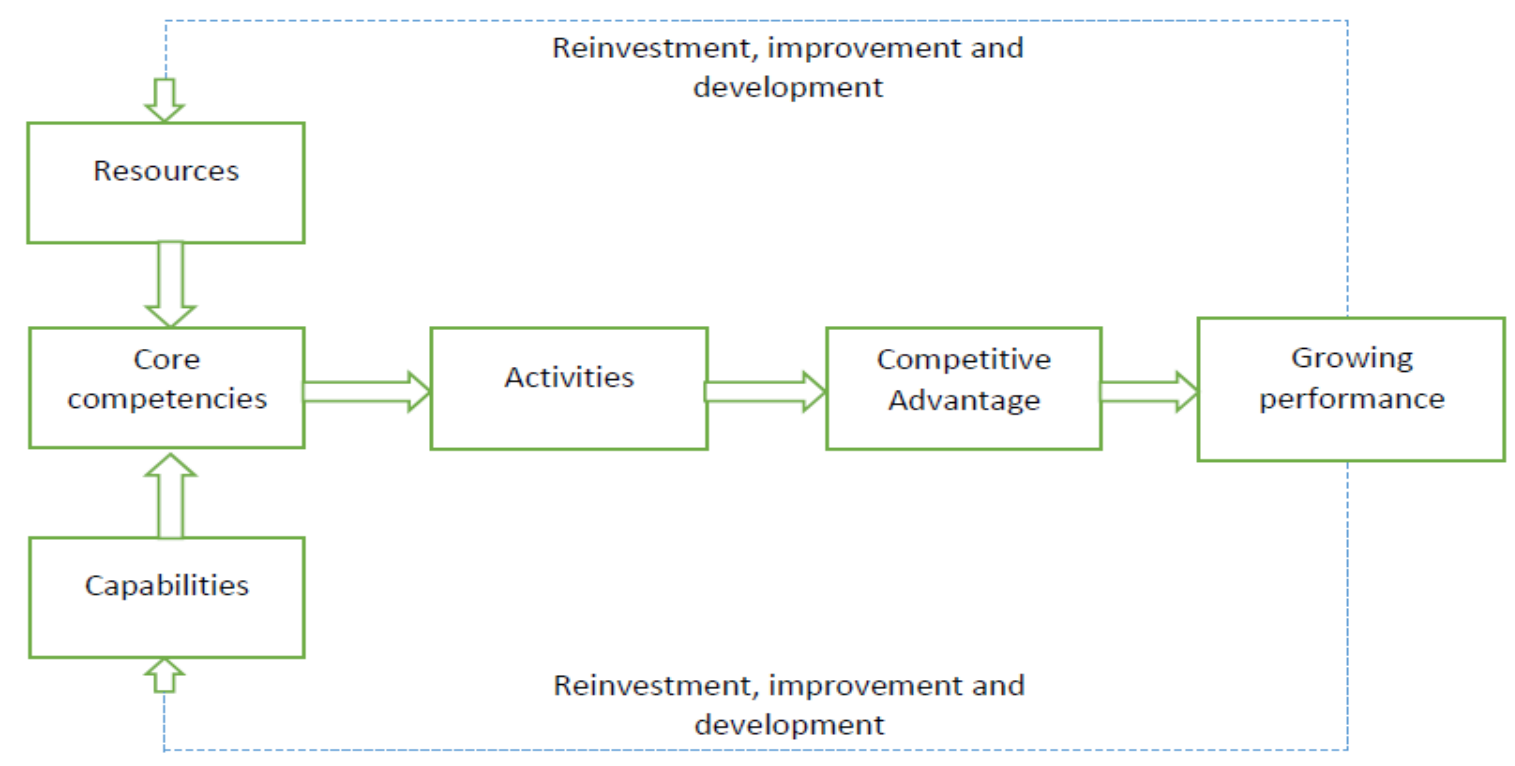

Figure 1. The incidence of core competencies, resources, capabilities and activities on the organisation's competitive advantage and performance [1]

\section{METHODS OF VALUATING INTANGIBLE RESOURCES}

Knowledge is a valuable asset to organisations which is not readily being recognised [2]. More of that, the role of intangible resources and human capital was critical for the success of the systemic transformation that took place in Central and Eastern Europe during the last decades [3]. Being intangible resources, measuring them, though subject to many scientific studies, is quite controversial. As we will state below, any rating methodology can be challenged in some ways because each model has its advantages and disadvantages, depending on the reason and objectives of the evaluation. However, researchers, practitioners and international organisations are constantly looking for new ways of refinement.

There are a lot of methods used to measure intangible resources. In the works of Sveiby [4], [5], Bontis [6], [7], Luthy [8], Williams [9], Petty, Guthrie [10], Andriessen [11], Sanchez et al. [12], Tan et al. [13], Jurczak [14], Nazari [15] and others, a large number of different methods (over 30) are identified. The large number of methods is probably the result of the fact that the research on intangible assets and intellectual capital initially resulted from the desires of practitioners to create and develop sophisticated measurement tools and methods, which meant a great progress.

After a thorough analysis of various intangible resource valuation methods and models used by theoreticians and practitioners (here, it is worth mentioning that a reference in structuring these methods is Sveiby's classification, based on Luthy and Williams' research, in whose approach, methods are divided into four categories: direct methods of measuring intellectual capital, methods based on market capitalisation, on asset returns and methods based on scores), we consider that they should be grouped into two large groups, in the light of determining intangible resources, in terms of value and nonvalue: quantitative and qualitative methods. Within these, we are pursuing another classification criterion, which covers the scope of valuating intangible resources, which means the distinction between the holistic methods, in the sense of the unitary analysis of an organisation's entire intangible resource system; atomistic or partial methods that involve analysing and evaluating each intangible resource, that is, by components. A presentation of some of the most important methods established in the literature, according to the structure presented above, is made in Figure 2.

\subsection{Qualitative Methods for Assessing Intangible Resources}

These non-financial methods are mostly based on scores and involve the identification of intangible resource components for which indicators are set in the form of scores (they are atomistic methods). Based on multiple indicators, composite indicators can also be generated. These methods are complex and costly due to the large number of components, which need to be individually identified and measured but they are also the most accurate way to measure the value of intangibles, taking into account that the other methods report their total value,36 
but they do not have any components.

\subsection{Quantitative Methods for Assessing Intangible Resources}

These can be of two types, either at the level of components of intangible resources - atomistic or at organisational level holistic.
1. Atomistic methods (at component level). Here direct methods of measuring intellectual capital are emphasised (Sveiby, 2001) which succeeded to estimate the monetary value (symbolically called value and expressed in monetary units) of intangible resources by identifying their components. As these components are identified, they can be directly valuate either individually or in the form of an aggregated coefficient.

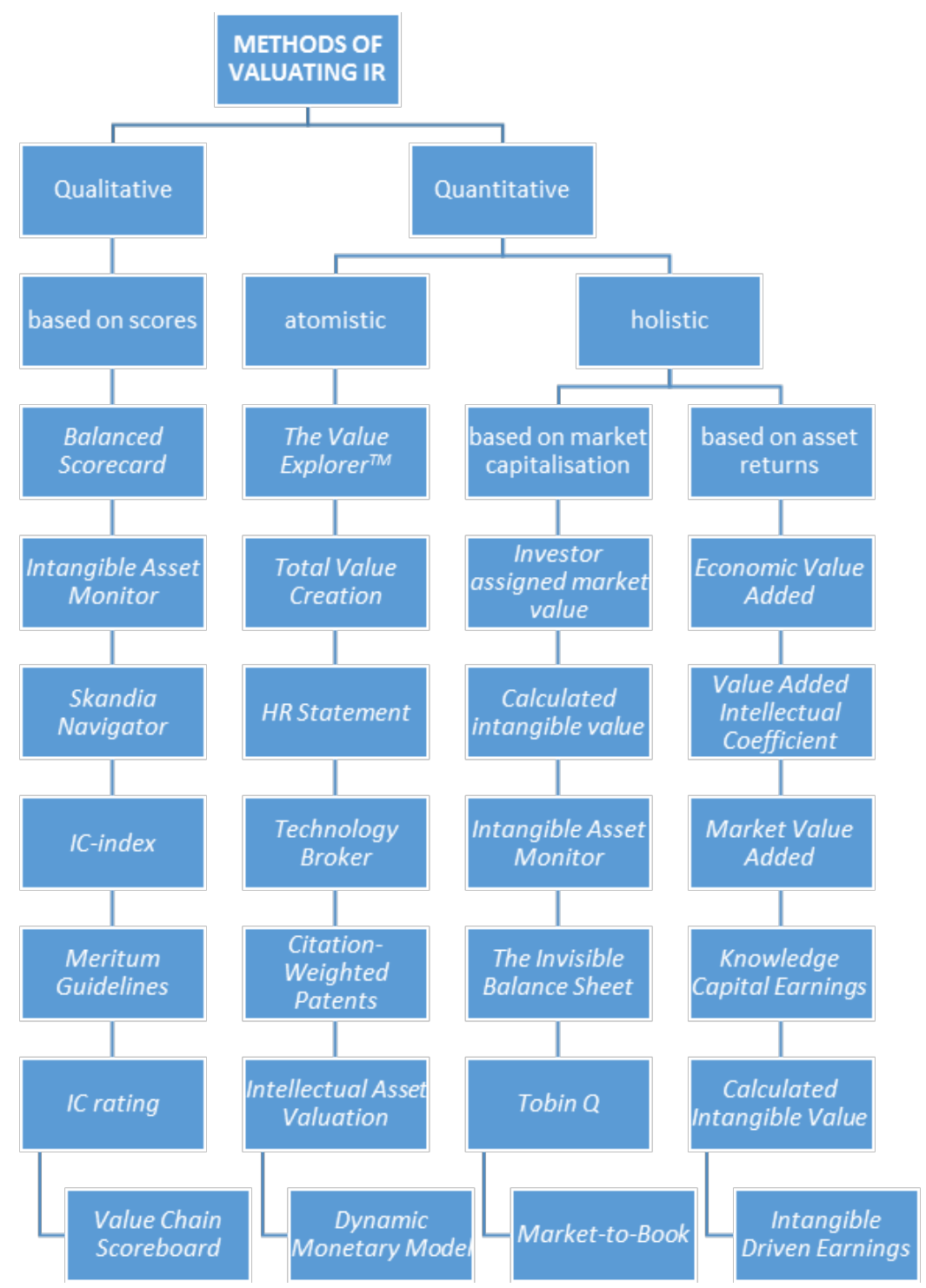

Figure 2. Methods of valuating intangible resources.

2. Holistic methods (at organisation level). These financial methods measure the value of intangible resources in monetary values at the organisation level, without referring to their components. Most of these methods use financial criteria in valuating intangible resources, thus providing only a global value. They are divided into two categories:

a) Methods based on market capitalisation, which calculates the difference between a firm's capitalisation (value) on the market and the shareholder's equity, recorded in the accounting statements, a difference that is considered to be generated by the value of its intangible resources.

b) Methods based on asset returns. A firm can compare such a rate with industry average and calculate the difference. If this difference is positive, it is assumed that the firm has a higher value of intangible resources compared to the industry.
These models have both strengths and weaknesses. If some of the models are easy to implement, the relevance of the information obtained may be rather small. Other models offer a more comprehensive and objective view of intangible resources, but some organisations may encounter difficulties in their application.

\section{CONCLUSIONS}

Starting from the study of the specialised literature on the methods of valuating intangible resources, we affirm that it is very difficult to implement a universally accepted valuation method from an accounting perspective. However, all the evaluation methods discussed offer ideas that may be adapted, developed and may even be implemented to a certain extent in the practical environment, having as purpose the attribution of a value to intangible resources.

Regardless of all these methods of evaluation and monitoring 37 
of known intangible resources, we state that the methodology used for this process, in the future must be in the management's attention of any organisation. The importance of financial indicators within the firm is already known, so in the context of knowledge-based economy, organisation, and management, the need for valuation and invisible intangible resources is obvious.

In fact, the goal we are pursuing, both through the present and ongoing research, is to modify the current situation where information and reporting of organisations related to their intangible resources are limited and based on incomplete and heterogeneous conceptions, towards a new scenario in which we will have homogeneous, reliable, verifiable and comparable information on the intangible determinants of the value of organisations.

\section{REFERENCES}

1. Rothaermel F. T., Strategic management, third Edition, McGraw-Hill Education, pg. 110 (2017).

2. Holifield D., Clarke T., Jones E., Sustainability of Knowledge within Organisations, Management of Sustainable Development, 3(2), pp. 3-7 (2011).

3. Bochniarz Z., Mandova K., Stefanescu R., The Role of Human Capital in Central and East European Transformation: the Case of Bulgaria, Management of Sustainable Development, 4(2), pp. 5-10 (2012).

4. Sveiby K. E., Challenging the Innovation Paradigm, Routledge (2012).

5. Sveiby K.E., A Knowledge-Based Theory of The Firm To Guide In Strategy Formulation, Journal of Intellectual Capital, 2(4), pp. 344-358 (2001).

6. Bontis N., Assessing knowledge assets: a review of the models used to measure intellectual capital, International Journal of Management Reviews, 3(1), pp. 41-60 (2001).

7. Bontis N., Managing organizational knowledge by diagnosing intellectual capital: Framing and advancing the state of the field, International Journal of Technology Management, 18(5), pp. 433-462 (1999).

8. Luthy D. H., Intellectual capital and its measurement, Asian Pacific Interdisciplinary Research in Accounting (APIRA) Conference, Osaka, available online at: www3.bus.osaka-cu.ac.jp/apira98/archives/htmls/25. htm, pp. 6 (1998).

9. Williams M., Is a company's intellectual capital performance and intellectual capital disclosure practices related? Evidence from publicly listed companies from the FTSE 100, working paper: Mc Masters Intellectual Capital Conference, Toronto, Canada (2000).

10. Petty R., Guthrie J., Intellectual capital literature review: Measurement, reporting and management, Journal of Intellectual Capital, 1(2), pp. 155-176 (2000).

11. Andriessen D., IC valuation and measurement: classifying the state of the art, Journal of Intellectual Capital, 5(2), pp. 230-242 (2004).

12. Sanchez M. P., Chaminade C., Olea M., Management of intangibles: an attempt to build a theory, Journal of Intellectual Capital, 1(4), pp. 312-327 (2000).

13. Tan H. P., Plowman D., Hancock P., The Evolving research on intellectual capital. Journal of Intellectual Capital, 9(4), pp. 585 - 608. doi: 10.1108/ 14691930810913177 (2008).

14. Jurczak J., Intellectual Capital Measurement Methods, Institute of Organization and Managment in Industry „ORGMASZ” 1(1), pp. 37 - 45, 10.2478/v10061-0080005-y (2008).

15. Nazari J. A., An Investigation of the Relationship between the Intellectual Capital Components and Firm's Financial Performance, available online at: https://www.researchgate.net/profile/Jamal Nazari2/public ation/282134314 An Investigation of the Relationship between the Intellectual Capital Components and Firm' $\underline{\text { s Financial Performance/links/5604498008ae8e08c089ac }}$ fc.pdf (2010). 